
\title{
BReserch Soute \\ Regulation of Subsoiling Tillage on the Grain Filling Characteristics of Maize Varieties From Different Eras
}

\section{Li-qing WANG}

Inner Mongolia Agricultural University

Xiao-Fang YU ( $\nabla$ nmyuxiaofang@imau.edu.cn )

Inner Mongolia Agricultural University

Ju-Lin GAO

Inner Mongolia Agricultural University

Da-Ling MA

Inner Mongolia Agricultural University

\section{Liang LI}

Inner Mongolia Agricultural University

\section{Shu-Ping HU}

Inner Mongolia Agricultural University

\section{Research Article}

Keywords: spring maize, subsoiling tillage, grain filling

Posted Date: March 1st, 2021

DOI: https://doi.org/10.21203/rs.3.rs-243081/v1

License: () (1) This work is licensed under a Creative Commons Attribution 4.0 International License.

Read Full License 


\title{
Regulation of subsoiling tillage on the grain filling
} characteristics of maize varieties from different eras

\author{
Li-qing WANG ${ }^{1}$, Xiao-Fang YU ${ }^{*}$, Ju-Lin GAO ${ }^{*}$, Da-Ling MA${ }^{1}$, Liang $\mathrm{LI}^{1}$,Shu-Ping HU ${ }^{1}$ \\ 1 Inner Mongolia Agricultural University, No.275, XinJian East Street, Hohhot 010019, China; \\ nmwangliqing@emails.imau.edu.cn (L.-Q.W.); nmyuxiaofang@imau.edu.cn (X.-F.Y.); \\ nmgaojulin@163.com (J.-L.G.); 2979187605@qq.com (L,L); madaling@sina.com (D.-1.M.); bthsp88@163.com \\ (S.-p.H.) \\ *Correspondence: nmyuxiaofang75@imau.edu.cn (X.-F.Y.);nmgaojulin@163.com (J.L.G.) \\ Tel.: +86-136-7482-7018
}

\begin{abstract}
Grain filling is the key stage for achieving high grain yield. Subsoiling tillage has been widely used as a conservation tillage method in the maize planting region of China. This study was conducted to explore the effects of subsoiling on the grain filling characteristics of maize varieties of different eras. Five typical maize varieties from different eras (1970s, 1980s, 1990s, 2000s and 2010s) were used as trial materials with two tillage modalities: rotation tillage and subsoiling tillage. The characteristic parameters and rate parameters of grain filling were compared and analyzed using the selected tillage modalities. The results showed that the grain filling parameters of the 2010s variety were better than those of the other varieties, and these differences mainly manifested in the filling rate parameters of the rapidly increasing and slowly increasing periods. In comparison with rotation tillage, subsoiling improved the maximum grain filling rate and the grain growth during the period of the maximum grain filling rate to different degrees. In addition, subsoiling delayed the appearance time of the maximum grain filling rate, extended the grain filling duration, and improved the mean filling rate. These differences are major reasons for the significant increase in 100-kernel dry weight at harvest for subsoiling in comparison with rotation tillage. Moreover, subsoiling enhanced the filling rate parameters during the rapidly increasing and slowly increasing periods. The filling stage filling duration and filling rate of maize varieties of different eras showed different responses to subsoiling. For example, the grain filling rate parameters of the 2010s variety during the rapidly increasing period were more sensitive to subsoiling in comparison with those of the other varieties.
\end{abstract}

Key words: spring maize; subsoiling tillage; grain filling

\section{Introduction}

Analysis of reports about maize high yield records in China and elsewhere show that increasing maize yield depends on sufficient water and fertilizer conditions, varieties with high yield and density tolerance, high planting density and reasonable cultivation measures ${ }^{[1-2]}$. Therefore, in the context of the rigid demand for maize grain yield, the reduction of cultivated land area and aggravation of water resource shortages in China, soil fertility improvement, maize variety improvement and innovative cultivation techniques have become effective ways 
to optimize maize yield per unit area.

It is inevitable that increasing plant density leads to decreased grain yield. In addition, the advantages and disadvantages of topsoil structure further affect the population capacity ${ }^{[3]}$. A tillage layer with good structure can alleviate the adverse effects of increased density, and practices that optimize this structure are key measures for optimizing maize yield in China. As a conservation tillage measure, subsoiling can effectively improve soil physical and chemical properties, enhance plant self-regulation ability, alleviate the cluster effect of densification, effectively stabilize population yield and realize densification and yield improvement ${ }^{[4-5]}$.

Previous work has shown that grain filling is an important physiological process that determines the yield and quality of maize grain[-6]]. Therefore, by matching appropriate tillage practices[8-9], varieties ${ }^{[10-11]}$, planting density ${ }^{[12-13]}$ and management measures ${ }^{[14]}$, as well as constructing a reasonable group structure to realize full utilization of light, heat, water and fertilizer resources, good filling conditions can be established to achieve coordination of ear number, ear grain number and grain weight, which finally increase the maize yield per unit area.

Studies have shown that subsoiling promoted maize root penetration, increased the photosynthetic rate and delayed leaf senescence, which increased planting density and maize yield ${ }^{[15-17]}$. However, few studies have assessed the effects of subsoiling on maize grain filling characteristics. Therefore, using maize varieties from different eras as experimental materials, the aim of this study was to analyze the effects of subsoiling on grain filling characteristics to provide a basis for further exploration of the mechanisms underlying increases in planting density and maize yield.

\section{Materials and methods}

\subsection{Trials and measurements}

Field experiment were carried out at the Tumoteyou Qi Experimental Station of the Inner Mongolia Agricultural University $\left(40^{\circ} 33^{\prime} \quad\right.$ N, 110 $31^{\prime} \quad$ E) during 2018 and 2019. The soil type was sandy loam, and the $0-30 \mathrm{~cm}$ soil layer contained $22.27 \mathrm{~g} \cdot \mathrm{kg}^{-1}$ of organic matter, 103.75 $\mathrm{mg} \cdot \mathrm{kg}^{-1}$ available nitrogen, $15.76 \mathrm{mg} \cdot \mathrm{kg}^{-1}$ available phosphorus, and $219.60 \mathrm{mg} \cdot \mathrm{kg}^{-1}$ available potassium ( $\mathrm{pH}$ 8.23). The main meteorological factors during the maize growth period are given in Fig. 1.
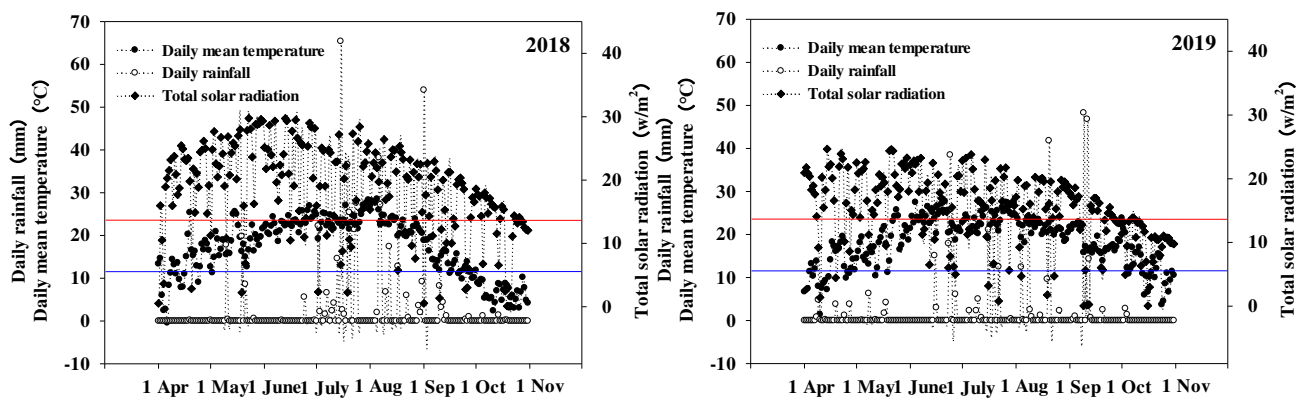

Fig. 1 Main meteorological factors during the growth period in the experimental area

The trial used a two-factor split-plot design (tillage treatment and variety). Tillage treatment was the main plot, and the two tillage practices were subsoiling (SS) with a depth of $35 \mathrm{~cm}$ and rotary tillage (RT) with a depth of $15 \mathrm{~cm}$. The main plot contained subplots with each variety: ZD2 (1970s), DY13 (1980s), YD13 (1990s), XY 335 (2000s), and DH618 (2010s). These varieties are sold in the Chinese market and allowed to be purchased as test materials. 
The planting density was 75000 plants $\bullet \mathrm{hm}^{-2}$. Interline planting was used with a row spacing of $0.6 \mathrm{~m}$. The plot length and width were each $6 \mathrm{~m}$, and the trial area was $6 \times 6 \mathrm{~m}$. The dosages of $\mathrm{N}, \mathrm{P}_{2} \mathrm{O}_{5}$ and $\mathrm{K}_{2} \mathrm{O}$ were $465 \mathrm{~kg} \bullet \mathrm{hm}^{-2}, 210 \mathrm{~kg} \bullet \mathrm{hm}^{-2}$, and $202.5 \mathrm{~kg} \bullet \mathrm{hm}^{-2}$, respectively. $\mathrm{P}_{2} \mathrm{O}_{5}$ and $\mathrm{K}_{2} \mathrm{O}$ were applied as basal fertilizer at seeding. At V6, V12, and R2, N was applied as fertilizer at the ratio of 3:6:1. Subsoiling was achieved with a five-shovel subsoiling plough, and the traction power source was a John Deere 1654 tractor. The plots were irrigated four times during the growth period (seeding stage, V12, R1 and R2) at a rate of $750 \mathrm{~m}^{3} / \mathrm{hm}^{2}$. The main soil physical characteristic indexes in the trial area are given in Table 1.

Table 1 Main soil physical properties in the test area

\begin{tabular}{cccccc}
\hline \multirow{2}{*}{ Years } & \multirow{2}{*}{ Tillage method } & \multicolumn{3}{c}{ VE } \\
\cline { 3 - 6 } & & $\begin{array}{c}\text { Soil compaction } \\
(\mathrm{Kpa})\end{array}$ & $\begin{array}{c}\text { Soil moisture } \\
\text { content }\end{array}$ & $\begin{array}{c}\text { Soil compaction } \\
(\text { Kpa })\end{array}$ & $\begin{array}{c}\text { Soil moisture } \\
\text { content }\end{array}$ \\
\hline \multirow{2}{*}{2018} & RT & 2194.19 & 0.17 & 2675.5 & 0.15 \\
& SS & 1775.23 & 0.19 & 2443.14 & 0.16 \\
& RT & 2352.46 & 0.17 & 1333.41 & 0.19 \\
& SS & 1850.77 & 0.14 & 1143.86 & 0.16 \\
\hline
\end{tabular}

\subsection{Measurement}

\subsubsection{Grain filling characteristics}

From 15 days after pollination, samples were collected at 3-day intervals until the end of filling. At each sampling point, three ears were collected per plot, and 100 kernels were collected from the middle of each ear. The kernels were weighed and placed into an oven for $30 \mathrm{~min}$ at $105{ }^{\circ} \mathrm{C}$, after which they were dried at $80^{\circ} \mathrm{C}$ to a constant weight, and their weight was measured ${ }^{[10]}$. The collection of experimental material, which complied with relevant institutional, national, and international guidelines and legislation.

A logistic equation ${ }^{[18]}$ was used to fit the grain filling process, calculate grain filling characteristic parameters, and analyze grain filling growth. The logistic equation was calculated as follows:

$$
\mathrm{W}=\mathrm{A} /\left(1+\mathrm{Be}^{-\mathrm{Ct}}\right)
$$

In the equation above, $t$ is the number of days after flowering (blooming day $t_{0}=0$ ), $w$ is the 100-kernel weight after flowering (grain weight on flowering day= $\mathrm{w}_{0}$ ), $A$ is the theoretical maximum 100-kernel weight, and $B$ and $C$ are shape parameters. The filling parameters were derived from the first and second derivatives of the equation.

$\mathrm{t}_{1}$ (the start date of the filling peak period $)=(\ln B-1.317) / C$, corresponding to the grain weight $\left(\mathrm{w}_{1}\right)$ at this time: $\quad \mathrm{w}_{1}=\mathrm{A} /\left(1+\mathrm{Be}^{-\mathrm{C}+1}\right)$;

$\mathrm{t}_{2}$ (the end date of the filling peak period $)=(\ln \mathrm{B}+1.317) / \mathrm{C}$, corresponding to the grain weight ( $\left.\mathrm{w}_{2}\right)$ at this time: $\quad \mathrm{W}_{2}=\mathrm{A} /\left(1+\mathrm{Be}^{-\mathrm{Ct} 2}\right)$;

$t_{3}$ (the grain weight reaches 99\% after flowering, the effective filling period $)=(\ln B+4.59512) / C$, corresponding to the grain weight $\left(w_{3}\right)$ at this time.

The filling duration of the gradually increasing period was calculated as $T_{1}=t_{1}-t_{0}$. The increase in grain weight during the rapidly increasing period was calculated as $\mathrm{w}_{1}=\mathrm{W}_{1}-\mathrm{W}_{0}$. The mean filling rate of the gradually increasing period was calculated as $\mathrm{v}_{1}=\mathrm{W}_{1} / \mathrm{T}_{1}$.

The filling duration of the rapidly increasing period was calculated as $\mathrm{T}_{2}=\mathrm{t}_{2}-\mathrm{t}_{1}$. The increase in grain weight during the rapidly increasing period was calculated as $\mathrm{w}_{2}=\mathrm{W}_{2}-\mathrm{W}_{1}$. The mean filling rate of the rapidly increasing stage was calculated as $\mathrm{v}_{2}=\mathrm{W}_{2} / \mathrm{T}_{2}$.

The filling duration of the slowly increasing period was calculated as $\mathrm{T}_{3}=\mathrm{t}_{3}-\mathrm{t}_{2}$. The increase in grain weight of the slowly increasing period was calculated as $\mathrm{w}_{3}=\mathrm{W}_{3}-\mathrm{W}_{2}$. The mean filling rate of the slowly increasing stage was calculated as $\mathrm{V}_{3}=\mathrm{W}_{3} / \mathrm{T}_{3}$; 
The final grain growth was $A$. Tmax (maximum filling rate time)=lnB/C, Wmax (growth at the maximum filling rate $)=\mathrm{A} / 2, \mathrm{Rmax}$ (the maximum filling rate $)=(\mathrm{CWmax}) \bullet(1-\mathrm{Wmax} / \mathrm{A}), P$ (time to complete approximately $90 \%$ of total accumulation) $=6 / \mathrm{C}$, and vmean (the mean filling rate) $=\mathrm{W}_{3} / \mathrm{t}_{3}$.

2.2.2 Determination of grain weight

At physiological maturity, ten ears were randomly selected from each plot and air-dried, after which 100 kernels were collected from the middle of each ear and weighed, and this weight was converted to the hundred grain weight with $14 \%$ moisture content[19]. The determination of grain weight, which complied with GB/T 5519-2008 national standard.

\subsection{Statistical analysis}

Statistical analysis was performed using Microsoft Excel 2016 and SAS 9.4 statistical software. The factor analysis was carried out using SPSS 25.0. The filling dynamic fitting was carried out using Curve Expert 1.4 software, and Sigmaplot 12.5 was used to create figures.

\section{Results}

3.1 Effect of subsoiling on the 100-kernel weight of maize varieties from different eras

Analysis of variance showed that the effects of the different tillage methods, varieties and years on the 100-grain weight were significant at $p<0.01$. The interactions of tillage method $^{*}$ varieties and years* ${ }^{*}$ ears were also significant, but the effect of tillage method ${ }^{*}$ variety was not significant (Table 2 ).

Table 2 Variance analysis of the effect of tillage method and variety on the 100-grain weight of maize

\begin{tabular}{ccc}
\hline Source & DF & Mean Square \\
\hline Tillage method $(\mathrm{M})$ & 1 & $38.53^{* *}$ \\
Main area error & 2 & 1.27 \\
Variety (V) & 4 & $181.46^{* *}$ \\
$\mathrm{~V}^{*} \mathrm{M}$ & 4 & 0.40 \\
Secondary area error & 16 & 0.54 \\
Years & 1 & $7.95^{* *}$ \\
\hline
\end{tabular}

Note: "*" means significant difference, and "*** means extremely significant difference.

Under the rotation tillage (RT) condition, the mean grain weight of each of the 1970s-1990s varieties was lower than that of the 2010s variety, but the 100-kernel weight of DH618 (2010s) was significantly increased $(\mathrm{P}<0.05)$. Compared with ZD2, the 100-kernel weight of DY13, YD13, XY335, and DH618 increased by $1.17 \mathrm{~g},-1.14 \mathrm{~g}, 3.62 \mathrm{~g}$ and $7.24 \mathrm{~g}$ in 2018, respectively, and increased by $1.81 \mathrm{~g}, 1.99 \mathrm{~g}, 6.07 \mathrm{~g}$ and $10.50 \mathrm{~g}$ in 2019, respectively (Fig. 2).

Subsoiling tillage significantly increased the 100 -kernel weight of each variety $(\mathrm{P}<0.05)$. However, there were significant differences in the responses of the varieties to subsoiling. Compared with RT, the mean 100-kernel weight of ZD2, DY3, YD13, XY335 and DH618 for 2018-2019 increased by $1.14 \mathrm{~g}, 1.35 \mathrm{~g}, 1.69 \mathrm{~g}, 1.75 \mathrm{~g}$ and $2.09 \mathrm{~g}$, respectively. 


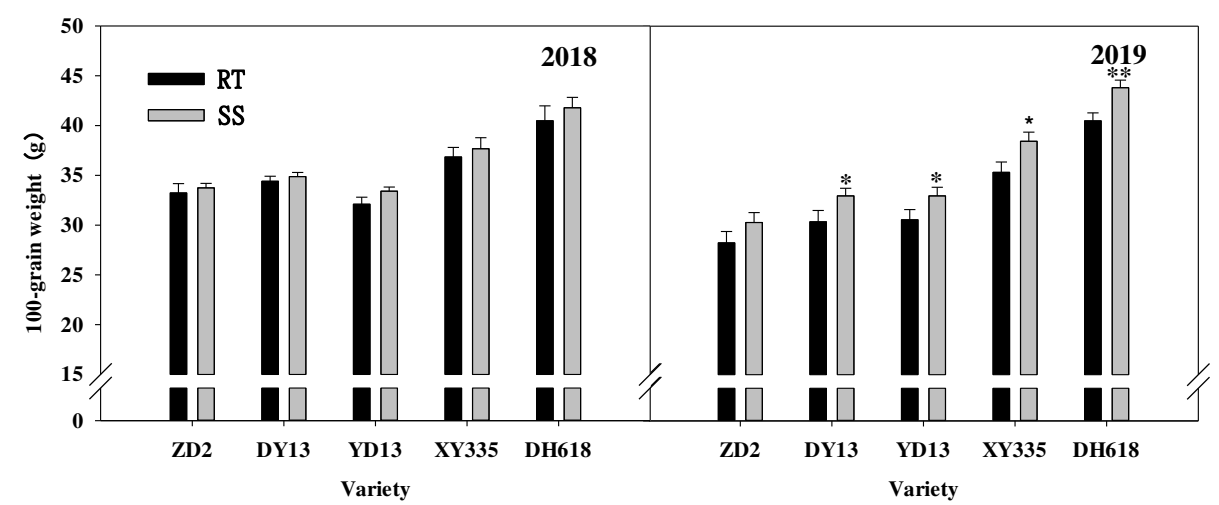

151

152

153

154

155

156

157

158

159

160

161

162

163

164

165

166

167

168

169

170

171

172

173

174

175

176

177

178

Fig. 2 Effects of deep loosening tillage on the 100-grain weight of different ages maize varieties 3.2 Effect of subsoiling on the kernel dry matter accumulation of maize varieties from different eras

As shown in Fig. 3, from 15 days after silking to physiological maturity, the kernel dry weight increased gradually, and maximum dry weight was achieved at physiological maturity. The kernel dry weight of the tested varieties showed no significant difference from $0-45 \mathrm{~d}$ after flowering; however, as the filling process continued, the difference increased progressively. The kernel weight of ZD2, DY13, YD13, XY335, and DH618 increased by $24.66 \mathrm{~g}, 23.91 \mathrm{~g}, 23.34$ $\mathrm{g}, 24.07 \mathrm{~g}$ and $24.49 \mathrm{~g}$, respectively, from 0-43 d after flowering in 2018, and it increased by 4.74 $\mathrm{g}, 6.19 \mathrm{~g}, 5.76 \mathrm{~g}, 10.52 \mathrm{~g}$ and $13.95 \mathrm{~g}$, respectively, from 43-75 d after flowering. In 2019, the kernel weight of ZD2, DY13, YD13, XY335, and DH618 increased by 22.03 g, 22.54 g, $20.91 \mathrm{~g}$, $21.18 \mathrm{~g}$ and $21.16 \mathrm{~g}$, respectively, from 0-43 d after flowering, and it increased by $6.89 \mathrm{~g}, 7.69 \mathrm{~g}$, $9.67 \mathrm{~g}, 13.19 \mathrm{~g}$ and $15.60 \mathrm{~g}$, respectively, from 43-75 $\mathrm{d}$ after flowering. These results show that the period from 45-75 d after flowering was the main stage during which significant differences between the kernel dry weight of the old and new varieties manifested.

Compared with RT, subsoiling tillage improved the kernel dry weight of the tested varieties, but the extent of the improvement of kernel dry weight by subsoiling was inconsistent for different filling processes. From 0-43 d after flowering in 2018, the kernel weight of ZD2, DY13, YD13, XY335, and DH618 changed by $-0.03 \mathrm{~g},-0.64 \mathrm{~g},-0.10 \mathrm{~g},-0.33 \mathrm{~g}$ and $-0.58 \mathrm{~g}$, respectively. However, from 43-75 d after flowering, the kernel weight increased by $0.43 \mathrm{~g}, 1.00$ g, $1.01 \mathrm{~g}, 1.38 \mathrm{~g}$ and $1.65 \mathrm{~g}$, respectively. In 2019, the kernel weight of ZD2, DY13, YD13, XY335, and DH618 changed by $0.18 \mathrm{~g},-0.10 \mathrm{~g},-0.23 \mathrm{~g},-0.53 \mathrm{~g}$ and $-1.13 \mathrm{~g}$, respectively, from $0-43 \mathrm{~d}$ after flowering, and the kernel weight increased by $1.84 \mathrm{~g}, 1.94 \mathrm{~g}, 1.85 \mathrm{~g}, 2.38 \mathrm{~g}$ and $3.69 \mathrm{~g}$, respectively, from 43-75 d after flowering. These results show that subsoiling mainly increased the kernel dry weight from 43-75 d after maize flowering, and the effect became more obvious as the originating era of the variety became more recent. 


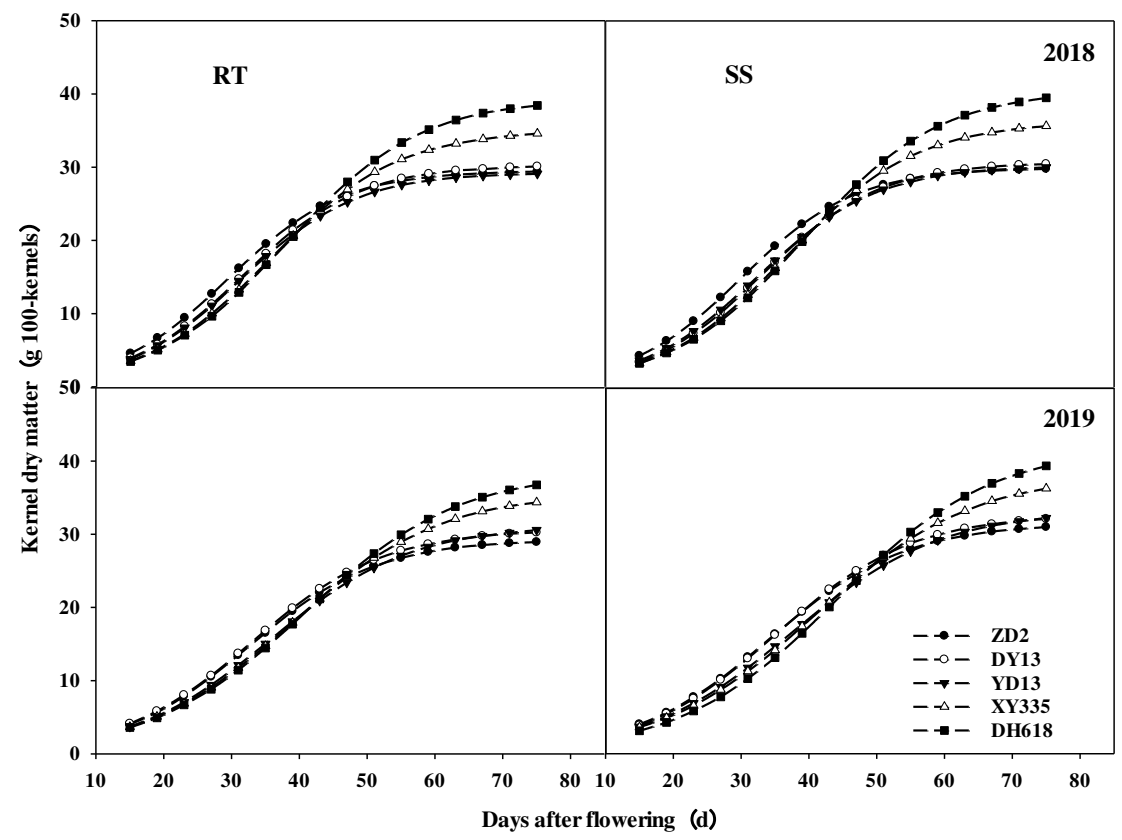

Fig. 3 Effects of deep loosening tillage on the dry weight of 100 grains of maize varieties in different ages

3.3 Effect of subsoiling on the filling characteristic of maize varieties from different eras

3.3.1 Fitting equation for the filling dynamic curves of maize varieties from different eras

The days after flowering $(t)$ and weight after flowering $(W)$ were used as the independent variable and dependent variable, respectively, in the logistic equation to simulate the grain filling process. According to the functional relationship between dry weight and days after flowering, the grain filling process was divided into three stages: gradually increasing stage, rapidly increasing stage and slowly increasing stage. The parameters of the fitting equation allowed the characteristic parameters of each filling stage to be obtained. The fitting equation determination coefficient $\left(R^{2}\right)$ of the filling process of the tested maize varieties was greater than 0.99 , so the logistic equation was determined to fit the grain filling process of maize varieties from different eras (Table 3).

Table 3. Fitting equation of the grain growth curve of each treatment

\begin{tabular}{|c|c|c|c|c|}
\hline Year & Tillage method & Variety & Fitting equation & $\mathrm{R}^{2}$ \\
\hline \multirow{10}{*}{2018} & \multirow{5}{*}{ RT } & ZD2 & $y=29.48 /\left(1+33.92^{*} \exp (-0.12 x)\right)$ & 0.997 \\
\hline & & DY13 & $y=30.26 /\left(1+39.44^{*} \exp (-0.12 x)\right)$ & 0.998 \\
\hline & & YD13 & $y=29.24 /\left(1+39.76^{*} \exp (-0.12 x)\right)$ & 0.998 \\
\hline & & XY335 & $y=35.04 /\left(1+45.05^{*} \exp (-0.11 x)\right)$ & 0.998 \\
\hline & & DH618 & $y=39.33 /\left(1+48.03^{*} \exp (-0.10 x)\right)$ & 0.998 \\
\hline & \multirow{5}{*}{ SS } & ZD2 & $y=29.89 /\left(1+37.33^{*} \exp (-0.12 x)\right)$ & 0.997 \\
\hline & & DY13 & $y=31.40 /\left(1+32.01^{*} \exp (-0.10 x)\right)$ & 0.997 \\
\hline & & YD13 & $y=30.68 /\left(1+46.74^{*} \exp (-0.12 x)\right)$ & 0.998 \\
\hline & & XY335 & $y=32.60 /\left(1+34.28^{*} \exp (-0.10 x)\right)$ & 0.997 \\
\hline & & DH618 & $y=30.20 /\left(1+41.96^{*} \exp (-0.12 x)\right)$ & 0.998 \\
\hline
\end{tabular}




\begin{tabular}{|c|c|c|c|c|}
\hline \multirow{10}{*}{2019} & \multirow{5}{*}{ RT } & ZD2 & $\mathrm{y}=29.21 /\left(1+32.02^{*} \exp (-0.11 \mathrm{x})\right)$ & 0.997 \\
\hline & & DY13 & $y=30.57 /\left(1+31.34^{*} \exp (-0.10 x)\right)$ & 0.997 \\
\hline & & YD13 & $\mathrm{y}=31.13 /\left(1+33.04^{*} \exp (-0.10 \mathrm{x})\right)$ & 0.998 \\
\hline & & XY335 & $\mathrm{y}=35.60 /\left(1+34.97^{*} \exp (-0.09 \mathrm{x})\right)$ & 0.997 \\
\hline & & DH618 & $\mathrm{y}=38.48 /\left(1+37.24^{*} \exp (-0.09 \mathrm{x})\right)$ & 0.998 \\
\hline & \multirow{5}{*}{ SS } & ZD2 & $\mathrm{y}=33.11 /\left(1+32.95^{*} \exp (-0.09 \mathrm{x})\right)$ & 0.997 \\
\hline & & DY13 & $y=36.23 /\left(1+50.59^{*} \exp (-0.11 x)\right)$ & 0.999 \\
\hline & & YD13 & $\mathrm{y}=38.02 /\left(1+36.39^{*} \exp (-0.09 \mathrm{x})\right)$ & 0.997 \\
\hline & & XY335 & $\mathrm{y}=40.56 /\left(1+53.28^{*} \exp (-0.10 \mathrm{x})\right)$ & 0.999 \\
\hline & & DH618 & $\mathrm{y}=41.89 /\left(1+46.78^{*} \exp (-0.09 \mathrm{x})\right)$ & 0.998 \\
\hline
\end{tabular}

195

3.3.2 Effect of subsoiling on the filling characteristic parameters of maize varieties from different eras

As shown in Table 4, the trends of the two-year trial data were basically consistent for filling characteristic parameters under the RT and subsoiling conditions. The filling parameters tended to increase, decrease, and then increase again during variety replacement over the last several decades; YD13 had the lowest values, and DH618 had the highest values. Therefore, the data for 2018 and 2019 were averaged for the following analysis. Under the RT condition, the $A$ values of ZD2, DY13, YD13, XY335 and DH618 were $29.35 \mathrm{~g}, 30.42 \mathrm{~g}, 30.19 \mathrm{~g}, 35.32 \mathrm{~g}$ and $38.91 \mathrm{~g}$, respectively; the Tmax values were $30.91 \mathrm{~d}, 32.25 \mathrm{~d}, 33.44 \mathrm{~d}, 37.23 \mathrm{~d}$ and $39.42 \mathrm{~d}$,

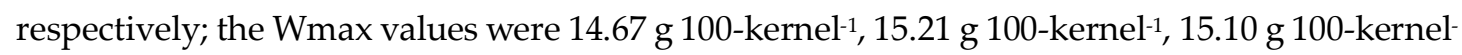

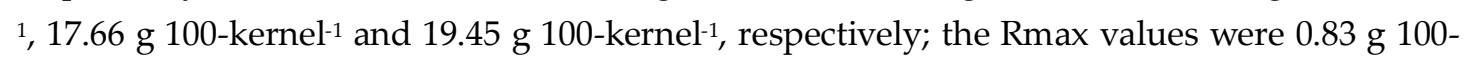
kernel $^{-1} \mathrm{~d}^{-1}, 0.84$ g 100-kernel ${ }^{-1} \mathrm{~d}^{-1}, 0.81{\mathrm{~g} 100-\text { kernel }^{-1} \mathrm{~d}^{-1}, 0.88 \text { g 100-kernel }}^{-1} \mathrm{~d}^{-1}$ and $0.93 \mathrm{~g} 100-$ kernel-1 $^{-1} \mathrm{~d}^{-1}$, respectively; the $P$ values were $53.09 \mathrm{~d}, 54.45 \mathrm{~d}, 56.02 \mathrm{~d}, 60.84 \mathrm{~d}$ and $63.31 \mathrm{~d}$,

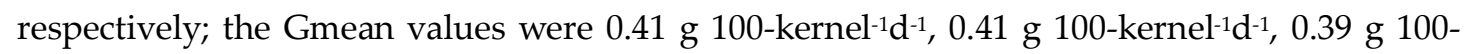

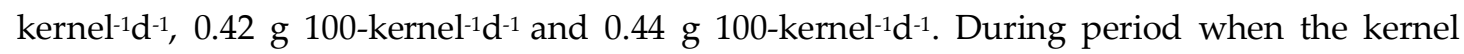
weight was increasing, all of the filling parameters of the modern varieties improved to different degrees.

For the subsoiling condition in comparison with RT, the $A$ values of ZD2, DY13, YD13, XY335 and DH618 increased by 4.43\%, 4.03\%, 5.02\%, 5.11\%, 5.96\%, respectively; the Wmax values increased by $4.46 \%, 4.01 \%, 4.84 \%, 5.12 \%$, and $5.96 \%$, respectively, the Rmax values increased by $1.81 \%, 1.79 \%, 1.23 \%, 2.29 \%$, and $4.86 \%$, respectively, the $\mathrm{P}$ values increased by $2.79 \%, 2.12 \%, 4.03 \%, 2.67 \%$, and $1.19 \%$, respectively, the Gmean values increased by $1.13 \%$, $0.29 \%, 0.55 \%, 1.56 \%$, and $2.59 \%$, respectively. These results indicate that subsoiling tillage can effectively control the filling characteristic parameters of different ages maize varieties, and the effect was more obvious with varieties that were generated more recently.

Table 4 Response of the grain filling characteristic parameters of maize varieties from different eras to tillage methods

\begin{tabular}{|c|c|c|c|c|c|c|c|c|}
\hline & & & $\mathrm{A}$ & Tmax & Wmax & $\operatorname{Rmax}$ & $\mathrm{P}$ & Gmean \\
\hline Year & Tillage method & Variety & (g) & (d) & $\begin{array}{l}\text { (g 100- } \\
\text { kernel-1) }^{-1}\end{array}$ & $\begin{array}{c}\text { (g 100-kernel- } \\
\left.{ }^{1} \mathrm{~d}^{-1}\right)\end{array}$ & (d) & $\begin{array}{c}\text { (g 100-kernel- } \\
{ }^{1} \mathrm{~d}^{-1} \text { ) }\end{array}$ \\
\hline \multirow{2}{*}{2018} & \multirow{2}{*}{ RT } & ZD2 & 29.48 & 29.36 & 14.74 & 0.88 & 49.99 & 0.432 \\
\hline & & DY13 & 30.26 & 31.47 & 15.13 & 0.88 & 51.39 & 0.423 \\
\hline
\end{tabular}




\begin{tabular}{|c|c|c|c|c|c|c|c|c|}
\hline & & YD13 & 29.24 & 31.22 & 14.62 & 0.86 & 50.86 & 0.413 \\
\hline & & XY335 & 35.04 & 35.64 & 17.52 & 0.94 & 56.16 & 0.441 \\
\hline & & DH618 & 39.33 & 38.07 & 19.66 & 1.00 & 58.99 & 0.468 \\
\hline & & ZD2 & 29.89 & 30.08 & 14.95 & 0.90 & 49.86 & 0.433 \\
\hline & & DY13 & 30.68 & 33.07 & 15.34 & 0.89 & 51.61 & 0.418 \\
\hline & SS & YD13 & 30.20 & 32.47 & 15.10 & 0.87 & 52.14 & 0.413 \\
\hline & & XY335 & 36.23 & 36.96 & 18.12 & 0.96 & 56.52 & 0.447 \\
\hline & & DH618 & 40.56 & 39.40 & 20.28 & 1.02 & 59.46 & 0.473 \\
\hline \multirow{10}{*}{2019} & \multirow{5}{*}{ RT } & ZD2 & 29.21 & 32.46 & 14.60 & 0.78 & 56.18 & 0.383 \\
\hline & & DY13 & 30.57 & 33.02 & 15.29 & 0.80 & 57.51 & 0.393 \\
\hline & & YD13 & 31.13 & 35.66 & 15.57 & 0.76 & 61.17 & 0.374 \\
\hline & & XY335 & 35.60 & 38.82 & 17.80 & 0.81 & 65.52 & 0.396 \\
\hline & & DH618 & 38.48 & 40.77 & 19.24 & 0.85 & 67.62 & 0.412 \\
\hline & \multirow{5}{*}{ SS } & ZD2 & 31.40 & 34.24 & 15.70 & 0.79 & 59.27 & 0.390 \\
\hline & & DY13 & 32.60 & 35.11 & 16.30 & 0.82 & 59.60 & 0.400 \\
\hline & & YD13 & 33.20 & 37.51 & 16.55 & 0.77 & 64.40 & 0.377 \\
\hline & & XY335 & 38.02 & 40.98 & 19.01 & 0.83 & 68.41 & 0.403 \\
\hline & & DH618 & 41.89 & 44.01 & 20.94 & 0.92 & 68.66 & 0.429 \\
\hline
\end{tabular}

2.3.3 Path analysis of grain filling characteristic parameters and 100-kernel weight

In order to clarify the direct and indirect relationships between grain filling parameters and maize grain kernel weight, path-coefficient analysis was performed for five filling characteristic parameters and 100-kernel weight (Table 5). Highly significant positive correlations were identified between Tmax, Wmax, $P$ and 100-kernel weight $(P<0.01)$, and significant positive correlations were identified between Rmax, Gmean and 100-kernel weight $(\mathrm{P}<0.05)$. The correlation coefficients were ranked as follows:Wmax $>\operatorname{Tmax}>\mathrm{P}>\mathrm{Rmax}>\mathrm{Gmean}$. Wmax and 100-kernel weight had a positive direct correlation, and their correlation coefficient was 0.939 . Tmax, Rmax, $P$ and Gmean showed positive indirect correlations mainly through Wmax and 100-kernel weight, and their correlation coefficients were $0.866,0.495,0.667$, and 0.484, respectively. Comprehensive analysis suggests the use of rational cultivation to postpone the appearance of the maximum filling rate during the kernel filling process, while increasing the maximum filling rate to increase kernel growth and achieve the goal of increasing 100-

240 kernel weight.

Table 5 Path analysis of grain filling characteristic parameters

\begin{tabular}{cccccccc}
\hline & $\begin{array}{c}\text { Correlatio } \\
\text { Index }\end{array}$ & $\mathrm{n}$ & \multicolumn{5}{c}{ Coupling diameter factor } \\
\cline { 5 - 8 } & coefficient & coefficient & $\mathrm{X} 1$ & $\mathrm{X} 2$ & $\mathrm{X} 3$ & $\mathrm{X} 4$ & $\mathrm{X} 5$ \\
\hline $\mathrm{X} 1$ & $0.893^{* *}$ & 0.209 & & 0.866 & -0.021 & -0.174 & 0.013 \\
$\mathrm{X} 2$ & $0.976^{* *}$ & 0.939 & 0.193 & & -0.059 & -0.138 & 0.041 \\
$\mathrm{X} 3$ & $0.540^{*}$ & -0.113 & 0.039 & 0.495 & & 0.040 & 0.079 \\
$\mathrm{X} 4$ & $0.683^{* *}$ & -0.191 & 0.191 & 0.677 & 0.023 & & -0.017 \\
\hline
\end{tabular}




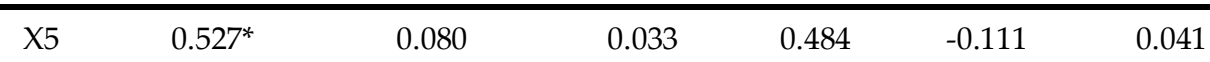

Note: X1 stands for Tmax, X2 stands for Wmax, X3 stands for Rmax, X4 stands for P, X5 stands for Gmean, and $Y$ stands for 100-grain weight. Tmax is the time when the maximum grouting rate was reached; Wmax is the grain growth at the maximum filling rate; Rmax is the maximum grouting rate; $\mathrm{P}$ is the active grouting stage; Gmean is the average grouting rate; $\mathrm{A}$ is the ultimate growth rate of the grain.

2.3.4 Effect of subsoiling on the filling rate parameters of maize varieties from different eras

The durations of each stage of maize grain filling were ranked as follows: slowly increasing stage>rapidly increasing stage>gradually increasing stage. The mean filling rates of each stage were ranked as follows: rapidly increasing stage>gradually increasing stage $>$ slowly increasing stage (Table 6). With the exception of the grain filling rate of the gradually increasing stage, the other grain filling rate parameters increased to different degrees during maize variety replacement over the last several decades. Under RT, the two-year mean T1 durations of ZD2, DY13, YD13, XY335, and DH618 were $19.26 \mathrm{~d}, 20.30 \mathrm{~d}, 21.14 \mathrm{~d}, 23.87 \mathrm{~d}$ and $25.52 \mathrm{~d}$, respectively, whereas those of T2 were $23.31 \mathrm{~d}, 23.91 \mathrm{~d}, 24.59 \mathrm{~d}, 26.71 \mathrm{~d}$ and $27.79 \mathrm{~d}$, respectively; and those of T3 were $29.01 \mathrm{~d}, 29.75 \mathrm{~d}, 30.61 \mathrm{~d}, 33.24 \mathrm{~d}$ and $34.59 \mathrm{~d}$. For ZD2, DY13, YD13, XY335, and

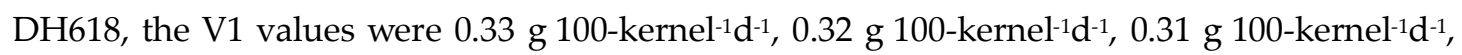

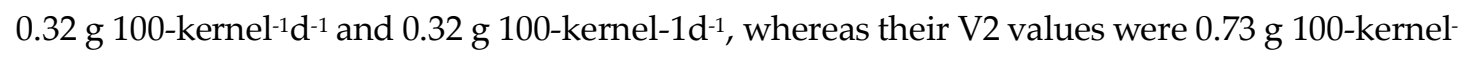

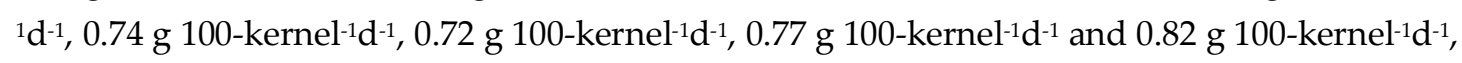

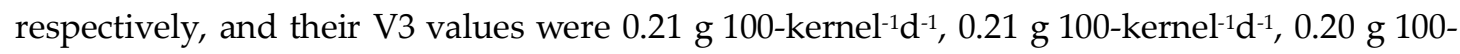
kernel-1 $^{-1} \mathrm{~d}^{-1}, 0.22 \mathrm{~g} 100$-kernel $^{-1} \mathrm{~d}^{-1}$ and $0.23 \mathrm{~g} 100$-kernel $^{-1} \mathrm{~d}^{-1}$.

Under the subsoiling condition, the grain filling duration was prolonged during different stages of grain filling in comparison with RT, and the increase in filling duration was greatest during the gradually increasing stage. The averaged two-year data revealed that the filling durations of ZD2, DY13, YD13, XY335, and DH618 were prolonged by $4.80 \%, 7.83 \%, 5.01 \%$, $5.80 \%$ and $8.33 \%$, respectively, during the gradually increasing stage. In addition, subsoiling increased the filling rate of ZD2, DY13, YD13, XY335, and DH618 during the rapidly increasing stage by $2.05 \%, 2.04 \%, 0.70 \%, 2.61 \%$, and $4.29 \%$, respectively, but it had little effect on the filling rate during other stages. These results indicate that subsoiling mainly extended the filling duration during the gradually increasing stage and improved the filling rate during the rapidly increasing stage. Moreover, maize varieties from more recent eras were found to be more sensitive to the effect of subsoiling in comparison with relatively older varieties.

273

Table 6 Response of grain filling rate parameters of different ages maize varieties to tillage methods

\begin{tabular}{|c|c|c|c|c|c|c|c|c|}
\hline Year & $\begin{array}{l}\text { Tillage } \\
\text { method }\end{array}$ & Variety & $\begin{array}{l}\text { T1 } \\
\text { (d) }\end{array}$ & (g 100-kernel-1-1-1) & $\mathrm{T} 2$ & (g 100-kernel-1 d-1) & $\mathrm{T} 3$ & (g 100-kernel-1 $\mathrm{d}^{-1}$ ) \\
\hline \multirow{6}{*}{2018} & \multirow{5}{*}{ RT } & ZD2 & 18.39 & 0.34 & 21.95 & 0.78 & 27.31 & 0.22 \\
\hline & & DY13 & 20.19 & 0.32 & 22.56 & 0.77 & 28.08 & 0.22 \\
\hline & & YD13 & 20.05 & 0.31 & 22.33 & 0.76 & 27.79 & 0.21 \\
\hline & & XY335 & 23.31 & 0.32 & 24.65 & 0.82 & 30.68 & 0.23 \\
\hline & & DH618 & 25.12 & 0.33 & 25.90 & 0.88 & 32.23 & 0.25 \\
\hline & SS & ZD2 & 19.14 & 0.33 & 21.89 & 0.79 & 27.24 & 0.22 \\
\hline
\end{tabular}




\begin{tabular}{|c|c|c|c|c|c|c|c|c|}
\hline & & DY13 & 21.74 & 0.30 & 22.66 & 0.78 & 28.20 & 0.22 \\
\hline & & YD13 & 21.03 & 0.30 & 22.89 & 0.76 & 28.48 & 0.21 \\
\hline & & XY335 & 24.55 & 0.31 & 24.81 & 0.84 & 30.88 & 0.24 \\
\hline & & DH618 & 26.35 & 0.33 & 26.10 & 0.90 & 32.49 & 0.25 \\
\hline \multirow{10}{*}{2019} & \multirow{5}{*}{$\mathrm{RT}$} & ZD2 & 20.13 & 0.31 & 24.66 & 0.68 & 30.70 & 0.19 \\
\hline & & DY13 & 20.40 & 0.32 & 25.25 & 0.70 & 31.42 & 0.20 \\
\hline & & YD13 & 22.23 & 0.30 & 26.85 & 0.67 & 33.42 & 0.19 \\
\hline & & XY335 & 24.43 & 0.31 & 28.77 & 0.71 & 35.80 & 0.20 \\
\hline & & DH618 & 25.92 & 0.31 & 29.68 & 0.75 & 36.94 & 0.21 \\
\hline & \multirow{5}{*}{ SS } & ZD2 & 21.23 & 0.31 & 26.02 & 0.70 & 32.38 & 0.20 \\
\hline & & DY13 & 22.03 & 0.31 & 26.17 & 0.72 & 32.57 & 0.20 \\
\hline & & YD13 & 23.37 & 0.30 & 28.27 & 0.68 & 35.18 & 0.19 \\
\hline & & XY335 & 25.96 & 0.31 & 30.03 & 0.73 & 37.37 & 0.20 \\
\hline & & DH618 & 28.94 & 0.31 & 30.14 & 0.80 & 37.51 & 0.22 \\
\hline
\end{tabular}

Note: T1 represents the grain filling duration of the gradually increasing stage, V1 represents the average grain filling rate of the gradually increasing stage, T2 represents the grain filling duration of the rapidly increasing stage, V2 represents the average grain filling rate of the rapidly increasing stage, T3 represents the grain filling duration of the slowly increasing stage, and V3 represents the average grain filling rate of the slowly increasing stage.

\subsubsection{Analysis of the grouting rate parameter factor}

In order to clarify the internal dependence of the grain filling rate and duration at each stage, factor analysis was performed using the two-year trial data (Table 7). Under RT, the factor load difference of the filling duration was small at each stage $(\mathrm{T} 1=0.96, \mathrm{~T} 2=0.96, \mathrm{~T} 3=0.96)$, which indicated that the proportion of the filling duration of each stage was nearly identical. Under subsoiling, the factor load difference of the grain filling duration between T1 and T2/T3 was large $(\mathrm{T} 1=0.91, \mathrm{~T} 2=0.97, \mathrm{~T} 3=0.97)$, which indicated that the effect of subsoiling on the grain filling duration was stronger during the rapidly increasing and slowly increasing stages. In addition, the factor load of the filling rate during the rapidly and slowly increasing stages was higher than that of the gradually increasing stage, which showed that the filling rate during the rapidly and slowly increasing stages contributed more to the mean filling rate in comparison with that of the gradually increasing stage. These results demonstrate that appropriate tillage measures can improve the filling rate during the rapidly increasing and slowly increasing stages, and thus improve the mean filling rate.

Table 7 Parameter factor analysis of grain filling rate

\begin{tabular}{ccccc}
\hline Farming methods & \multicolumn{3}{c}{ SS } & \multicolumn{3}{c}{ SS } \\
\cline { 2 - 5 } Index & Y1 & Y2 & Y1 & Y2 \\
\hline T1 & 0.961 & 0.249 & 0.914 & 0.340 \\
V1 & -0.414 & 0.766 & -0.055 & 0.721 \\
T2 & 0.958 & -0.233 & 0.970 & -0.211 \\
V2 & 0.021 & 0.985 & -0.001 & 0.983 \\
T3 & 0.958 & -0.234 & 0.971 & -0.210 \\
V3 & 0.022 & 0.992 & -0.069 & 0.971 \\
\hline
\end{tabular}


the average grouting rate. T1 represents the grain filling duration of the gradually increasing stage, V1 represents the average grain filling rate of the gradually increasing stage, T2 represents the grain filling duration of the rapidly increasing stage, V2 represents the average grain filling rate of the rapidly increasing stage, T3 represents the grain filling duration of the slowly increasing stage, and V3 represents the average grain filling rate of the slowly increasing stage.

\section{Discussion}

Previous studies have shown that the grain weight of maize is mainly determined by the filling rate and filling duration. Therefore, improving the grain filling rate and ensuring that grain filling is maintained for an appropriate duration could increase grain weight and yield[2023]. Fang et al.[24] showed that the grain filling rate determined dry matter accumulation and affected yield, and they showed that the implementation of a reasonable planting method could improve the grain filling rate. Gasura et al. ${ }^{[25]}$ reported that extending the active grain filling period and increasing the mean filling rate increased maize yield. Daynard et al.[26] found that prolonging the filling duration increased the 100-kernel dry weight of maize. On the basis of previous studies, the present study further explored the characteristics of maize grain filling and revealed that improving the mean filling rate and delaying the occurrence of the maximum filling rate led to increased grain growth during the period of the maximum filling rate. In addition, we found that the filling rates of the rapidly increasing and slowly increasing stages primarily determined the mean filling rate, whereas that of the gradually increasing stage had a weaker influence on the mean filling rate. Therefore, during the period from 20 days after silking to physiological maturity, which encompasses the rapidly increasing and slowly increasing stages of grain filling, the level of plant material accumulation was strongly correlated with the mean filling rate, and implementing practices that maximize plant dry matter accumulation will be beneficial to the further improvement of grain weight.

Conservation agriculture, such as the use of no tillage, less tillage, and straw mulch, has been an important strategy for the sustainable development of worldwide agriculture in the past few decades, because conservation agriculture can improve soil properties while increasing income and crop yields ${ }^{[27]}$. Farming methods are a key factor affecting soil systems in China, where soil management and seeding are mainly performed using small tractors, and a significant portion of farmland is subjected to methods involving less tillage or no tillage, which increase the surface soil bulk density and osmotic resistance, which have deleterious effects on crop growth ${ }^{[28-30]}$. Previous studies demonstrated that the use of optimized farming methods increased crop yield ${ }^{31-32]}$. For example, subsoiling increased yield by improving the 100-kernel weight of maize ${ }^{[33]}$. Zhai et al. ${ }^{[34]}$ showed that subsoiling increased the maximum and mean kernel filling rates, which significantly increased the maximum kernel weight at harvest. Cai et al.[35] et al. showed that subsoiling increased kernel weight, improved plant resistance to environmental stresses, and increased yield. In this study, we further analyzed the filling characteristics of maize varieties from different eras using subsoiling, and we showed that, compared with conventional rotation, subsoiling significantly improved kernel weight by increasing the maximum filling rate and prolonging the duration of the maximum grain filling rate. The beneficial effects of subsoiling on filling characteristics were likely observed because subsoiling tillage the bottom of the ploughed stratum, increased the topsoil depth, improved water storage and moisture conservation, promoted root growth and development ${ }^{[36-37]}$, 
maintained a high leaf area index and photosynthetic rate after anthesis, and slowed the subsequent decrease in photosynthetic rate. Therefore, the implementation of subsoiling tillage was beneficial for maize because it led to the production of more photosynthetic products ${ }^{[38]}$, thus increasing the grain filling rate and kernel weight.

\section{Conclusion}

During variety replacement over the last several decades, kernel weight was significantly increased, while kernel growth during the period of the maximum kernel filling rate was improved, the durations of the active filling period and maximum filling rate were prolonged, and the maximum filling rate and mean filling rate were increased. Compared with the other trial varieties, the 2010s variety had a longer gradually increasing period, and its filling rates during the rapidly increasing and slowly increasing period were improved to different degrees. Subsoiling tillage increased the maximum grain filling rate, postponed the occurrence of the maximum filling rate, prolonged the duration of the gradually increasing period, improved the filling rates of the rapidly increasing period and slowly increasing period, and increased grain weight. The filling rate of the rapidly increasing period of the 2010s variety was more sensitive to subsoiling tillage in comparison with the other trial varieties.

Author Contributions:Performed the experiments: L-q.W., J-l.G. and S-p.H. Analyzed the data: L-q.W., D-1.M. and X-f.Y.. Revised the manuscript critically for important intellectual content: X-f.Y., J-l.G. and D-1.M. ,Wrote the paper: L-q.W, L.L. and X-f.Y. .

\section{Funding:}

Acknowledgments: This study was supported by the National Natural Science Foundation of China (grant no. 31560360), the Science \& Technology Innovation Projects for High Yield and Efficiency of Grain (grant no. 2017YFD0300804), the National Maize Industrial Technology Systems (grant no. CARS-02-50), and the Crop Science Observation \& Experiment Station in Loess Plateau of North China, Ministry of Agriculture, P. R. of China (grant no. 25204120).

\section{Conflicts of Interest: Page: 12}

The authors declare no conflicts of interest.

\section{References}

1. Hai-Peng H, Wei M A, Noor M A, et al. Quantitative design of yield components to simulate yield formation for maize in China[J]. Journal of Integrative Agriculture, 2020, 019(003):P.668-679.

2. Li Shaokun, Wang Keru, Yang Xiaoxia, Han Dongsheng, Wang Yuhua, Xie Ruizhi, Hou Peng, Ming Bo. Technology and Benefit Analysis of High Yield Record Field in Maize.Crops,2017(06):1-6. (in Chinese with English abstract)

3. Shulan Wang, Hao Wang, Muhammad Bilal Hafeez, et al. No-tillage and subsoiling increased maize yields and soil water storage under varied rainfall distribution: A 9-year site-specific study in a semiarid environment. 2020, 255.

4. Yu Xiaofang, Sun Hongli, Gao Julin, Wang Zhigang, Yang Hengshan, Zhang Ruifu, Hu Shuping, Sun Jiying. Mechanism behind densification and yield increase of spring maize with different density-tolerance regulated by subsoiling [J]. Transactions of the Chinese Society of Agricultural Engineering,2019,35(13):35-46. (in Chinese with English abstract) 
5. Jr J L P, Aase J K. Water Infiltration and Storage affected by Subsoiling and Subsequent Tillage[J]. Soilence Society of America Journal, 2003, 67(3):859-866.

6. Li Q , Du L , Feng D, et al. Grain-filling characteristics and yield differences of maize cultivars with contrasting nitrogen efficiencies[J]. The Crop Journal, 2020.

7. Butts-Wilmsmeyer C, Seebauer J , Singleton L, et al. Weather During Key Growth Stages Explains Grain Quality and Yield of Maize[J]. Agronomy, 2019, 9(1).

8. Simi M, Dragievi V, Drini S M , et al. The Contribution of Soil Tillage and Nitrogen Rate to the Quality of Maize Grain[J]. Agronomy, 2020, 10(7):976.

9. Zhou B, Sun X, Wang D, et al. Integrated agronomic practice increases maize grain yield and nitrogen use efficiency under various soil fertility conditions[J]. The Crop Journal, 2019.

10. Li Q , Du L , Feng D, et al. Grain-filling characteristics and yield differences of maize cultivars with contrasting nitrogen efficiencies[J]. The Crop Journal, 2020.

11. Li-Xia S , Yan-Kai H , Ting L I . Top-grain filling characteristics at an early stage of maize(Zea mays L.) with different nitrogen use efficiencies[J]. Journal of Integrative Agriculture, 2017, 16(003):626639.

12. Jia Q , Sun L, Mou H, et al. Effects of planting patterns and sowing densities on grain-filling, radiation use efficiency and yield of maize (Zea mays L.) in semi-arid regions[J]. Agricultural Water Management, 2018:287-298.

13. Wei S , Wang X, Li G, et al. Plant Density and Nitrogen Supply Affect the Grain-Filling Parameters of Maize Kernels Located in Different Ear Positions[J]. other, 2019, 10. 2019, 10:180.

14. Ning-Ning Y U , Zhang J W , Liu P, et al. Integrated agronomic practices management improved grain formation and regulated endogenous hormone balance in summer maize (Zea mays L.)[J]. Journal of Integrative Agriculture, 2020, 19(7):1768-1776.

15. Xiaofang Yu,Qi Zhang,Julin Gao,Zhigang Wang,Qinggeer Borjigin,Shuping Hu,Baolin Zhang,Daling Ma. Planting Density Tolerance of High-Yielding Maize and the Mechanisms Underlying Yield Improvement with Subsoiling and Increased Planting Density[J]. Agronomy,2019,9(7).

16. Wu W , Wang S, Zhang L, et al. Subsoiling Improves the Photosynthetic Characteristics of Leaves and Water Use Efficiency of Rainfed Summer Maize in the Southern Huang-Huai-Hai Plain of China[J]. Agronomy, 2020, 10(4):465.

17. Amato, Mariana. Spatial Distribution of Roots and Water Uptake of Maize (Zea mays L.) as Affected by Soil Structure[J]. Crop Science, 2002.

18. Xiaohui Wang, Lei Zhang, Shuangli Liu, Yujun Cao, Wenwen Wei, Chunguang Liu, Yongjun Wang, Shaofeng Bian, Lichun Wang. Grain Filling Characteristics of Maize Hybrids Differing in Maturities [J]. Scientia Agricultura Sinica,2014,47(18):3557-3565. (in Chinese with English abstract)

19. GB/T 5519-2008, Determination of 1000-grain weight of cereals and legumes [S], China, National Food and Strategic Reserves Administration, 2012-10-11.

20. Youjia Chen, Gerrit Hoogenboom, Yuntao Ma, et al. Maize kernel growth at different floret positions of the ear. 2013, 149:177-186.

21. Borrás, Lucas, Zinselmeier C, Senior M L , et al. Characterization of Grain-Filling Patterns in Diverse Maize Germplasm[J]. Crop Science, 2009, 49(3).

22. Sadras V O, Egli D B . Seed Size Variation in Grain Crops: Allometric Relationships between Rate and Duration of Seed Growth[J]. Crop Science, 2008, 48(2):408.

23. Johnson D R, Tanner J W . Calculation of the Rate and Duration of Grain Filling in Corn (Zea mays 
L.)1[J]. Crop ence, 1972, 12(4).

24. Fang $\mathrm{H}, \mathrm{Gu} X$, Jiang $\mathrm{T}$, et al. An optimized model for simulating grain-filling of maize and regulating nitrogen application rates under different film mulching and nitrogen fertilizer regimes on the Loess Plateau, China[J]. Soil and Tillage Research, 199.

25. Gasura E , Setimela P , Edema R, et al. Exploiting Grain-Filling Rate and Effective Grain-Filling Duration to Improve Grain Yield of Early-Maturing Maize[J]. Crop ence, 2013, 53(6).

26. Daynard T B, Tanner J W, Duncan W G.Duration of the grain filling period and its relation to grain yield in corn, Zea mays L.[J].Crop Science, 1971, 11 (1) :45-48.

27. Gathala M K, Timsina J , Islam M S, et al. Conservation agriculture based tillage and crop establishment options can maintain farmers' yields and increase profits in South Asia's rice-maize systems: Evidence from Bangladesh[J]. Field Crops Research, 2015, 172:85-98.

28. Liu X B , Zhang X Y, Wang Y X, et al. Soil degradation: A problem threatening the sustainable development of agriculture in Northeast China[J]. Plant Soil \& Environment, 2010, 56(2):87-97.

29. Zhang X, Pei D, Chen S . Root growth and soil water utilization of winter wheat in the North China Plain[J]. Hydrological Processes, 2010, 18(12):-.

30. ?íp, Václav, Vavera R, Chrpová, Jana, et al. Winter wheat yield and quality related to tillage practice, input level and environmental conditions[J]. Soil \& Tillage Research, 2013, 132:77-85.

31. Piao L , Qi H , Li C , et al. Optimized tillage practices and row spacing to improve grain yield and matter transport efficiency in intensive spring maize[J]. Field Crops Research, 2016, 198:258-268.

32. Shi $Y, Y u Z$, Man J, et al. Tillage practices affect dry matter accumulation and grain yield in winter wheat in the North China Plain[J]. Soil and Tillage Research, 2016.

33. Zhang Ruifu, Yang Hengshan, Gao Julin, Zhang Yuqin, Wang Zhigang, Fan Xiuyan, Bi Wenbo. Effect of subsoiling on root morphological and physiological characteristics of spring maize[J]. Transactions of the Chinese Society of Agricultural Engineering,2015,31(05):78-84. (in Chinese with English abstract)

34. Lichao Zhai,Ping $\mathrm{Xu}$,Zhengbin Zhang, et al.Effects of deep vertical rotary tillage on dry matter accumulation and grain yield of summer maize in the Huang-Huai-Hai Plain of China[J]. Soil \& Tillage Research,2017,170:167-174.

35. Hongguang Cai, Wei Ma, Xiuzhi Zhang, et al. Effect of subsoil tillage depth on nutrient accumulation, root distribution, and grain yield in spring maize. 2014, 2(5):297-307.

36. Bian D , Jia G , Cai L, et al. Effects of tillage practices on root characteristics and root lodging resistance of maize[J]. Field Crops Research, 2016, 185:89-96.

37. Dahai Guan, Mahdi M. Al-Kaisi, Yushi Zhang, et al. Tillage practices affect biomass and grain yield through regulating root growth, root-bleeding sap and nutrients uptake in summer maize. 2014, 157:89-97.

38. Zhou Baoyuan, Sun Xuefang, Ding Zaisong, Ma Wei, Zhao Ming. Effect of Tillage Practice and Fertilization on Dry Matter Accumulation and Grain Yield of Summer Maize[J]. Scientia Agricultura Sinica,2017,50(11):2129-2140. (in Chinese with English abstract) 
Figures
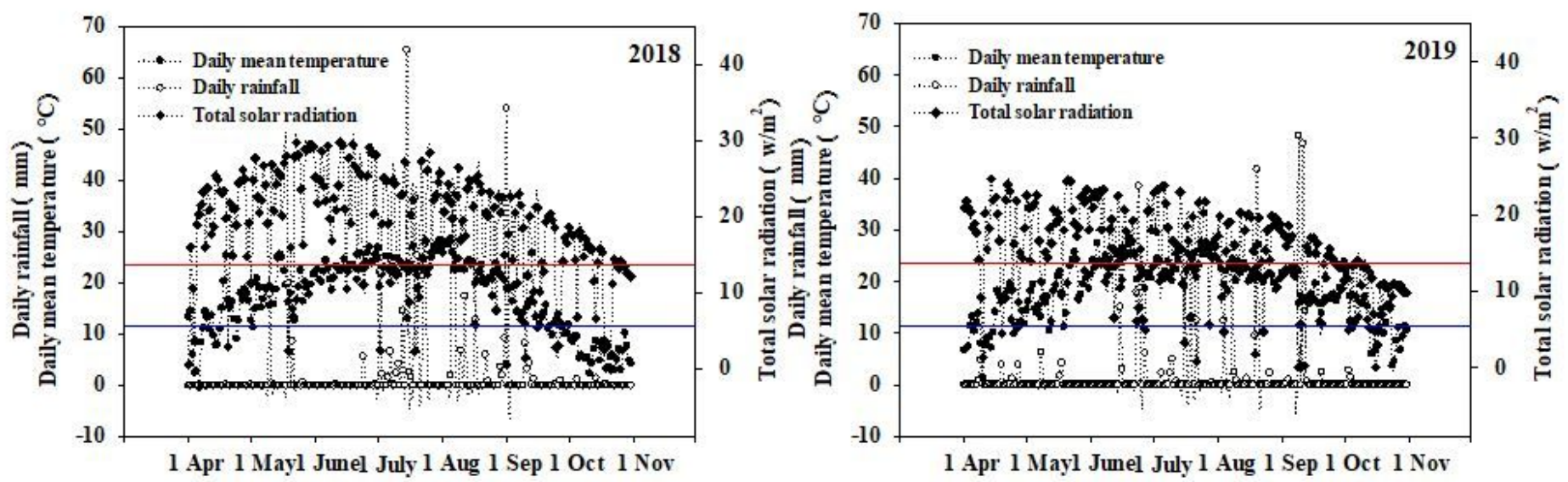

Figure 1

Main meteorological factors during the growth period in the experimental area

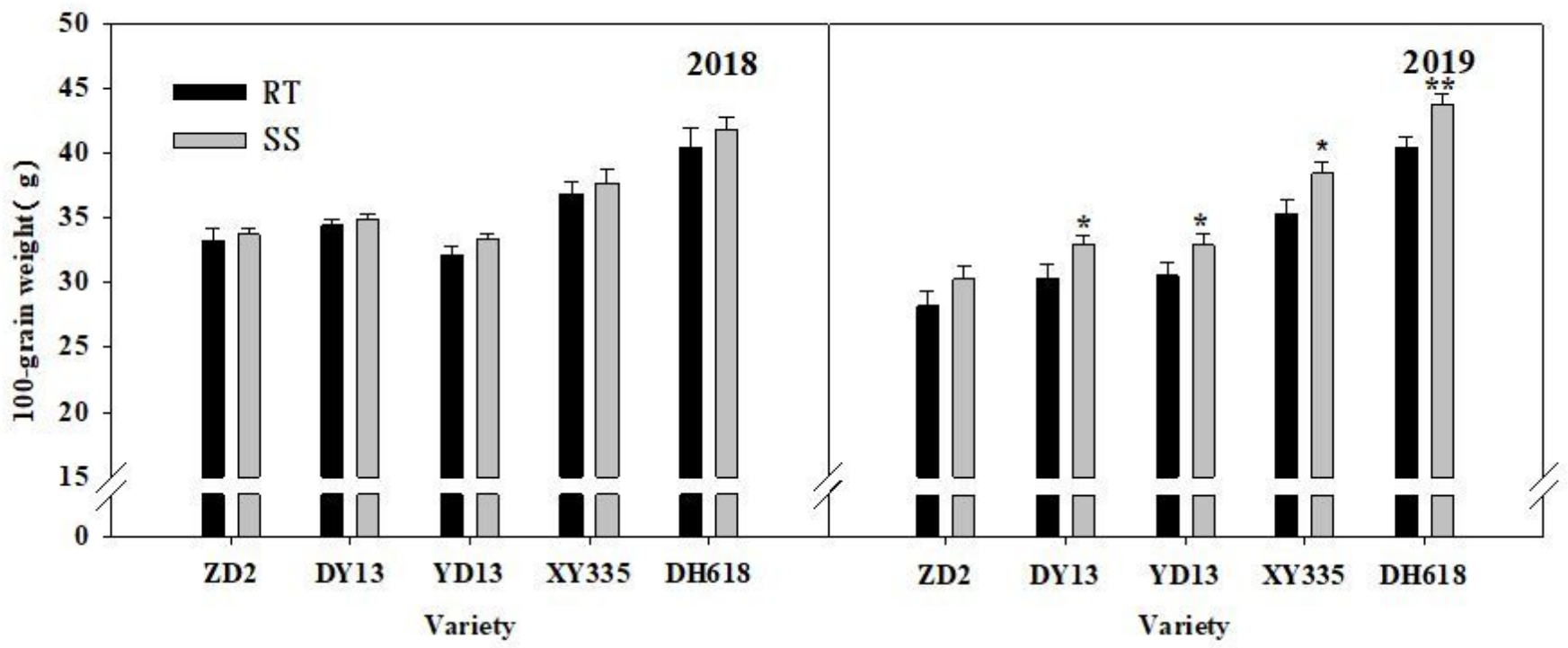

Figure 2

Effects of deep loosening tillage on the 100-grain weight of different ages maize varieties 3.2 Effect of subsoiling on the kernel dry matter accumulation of maize varieties from different eras 


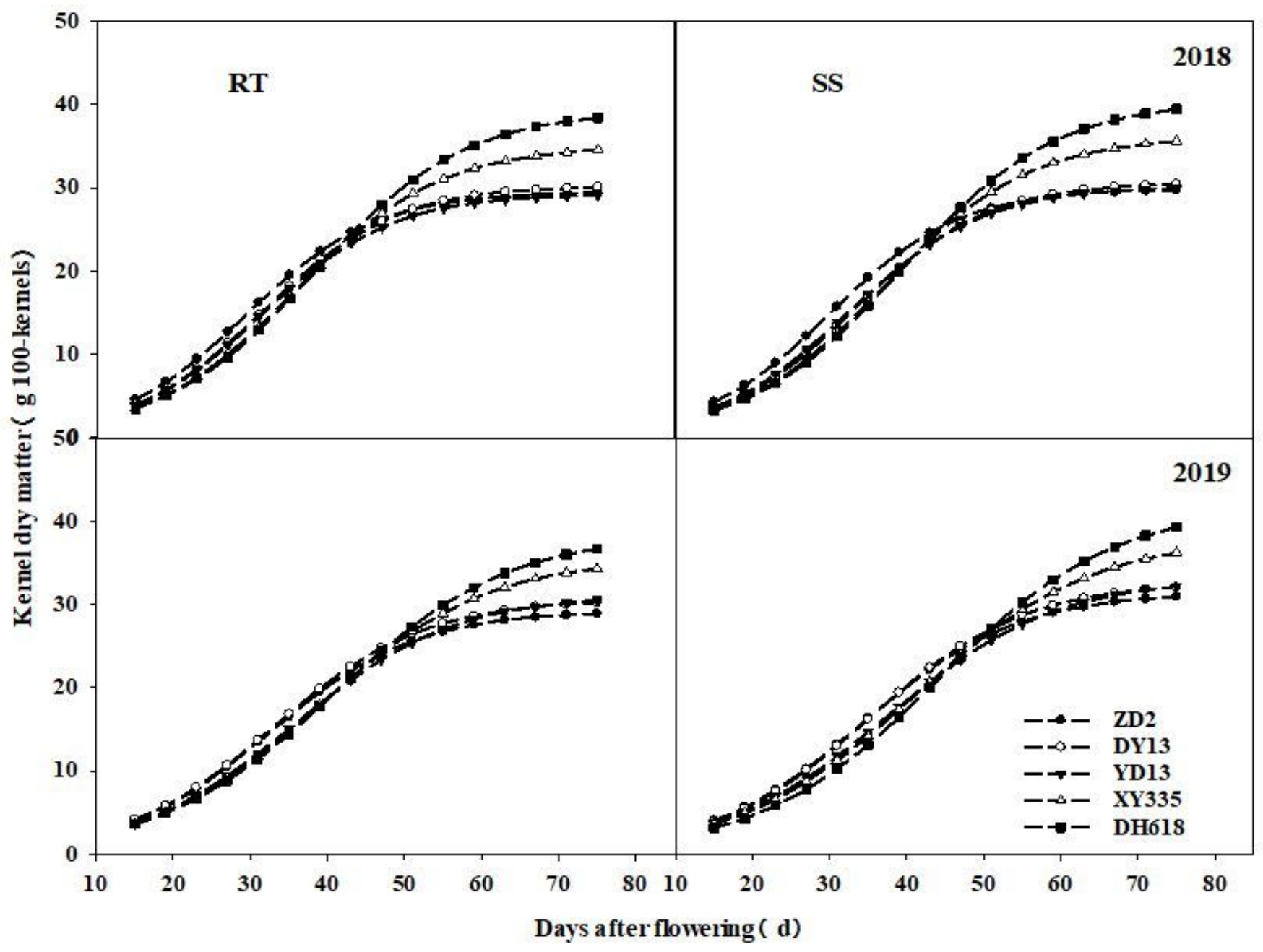

Figure 3

Effects of deep loosening tillage on the dry weight of 100 grains of maize varieties in different ages 